\title{
Inclusão escolar: dilemas e perspectivas
}

\section{Resumo}

O tema deste estudo é o sentido que a deficiência tem tomado ao longo da história humana, culminando nos dias atuais com a proposta de uma escola que busque um sentido de ampla inserção social, superando o preconceito para com os chamados "alunos problemáticos". Para além do conceito de integração de crianças portadoras de necessidades especiais, o que se constrói é o conceito de inclusão, isto é, que considere a existência de múltiplas diferenças entre os seres humanos, todos eles com direito à aprendizagem e ao convívio escolar. $\mathrm{O}$ artigo trata também do preconceito presente na escola contra os alunos que, por diferentes motivos, apresentam comportamento desajustado e que são, invariavelmente, rotulados como "indisciplinados".

\section{Abstract}

The object of this survey is the meaning that deficiency has assumed throughout human history, culminating nowadays with the proposal of a school that searches a sense o broad social insertion, overcoming the prejudice against the so called "problematic students". Beyond the concept of integration among children with special needs, what the concept of inclusion is built, which means that, considering the existence of multiple differences among human beings, all of them have the right to learn and the right for schoot living.

The article also approaches the prejudice present in schools against students that, for different reasons, present unadjusted behavior and who are often very labeled for different reasons, present unadjusted behavior and who are often very labeled as "undisciplined".

Ajustar-se a quê? A uma má cultura? A um pai dominador?

O que devemos pensar de um escravo bem ajustado? Parece claro que os problemas de personalidade podem, algumas vezes, ser sonoros protestos contra o esmagamento do "esqueleto" psicológico de alguém. Então, podemos considerar doentio não protestar, enquanto este crime está sendo cometido.

(Maslow, 1968, apud Klausmeier, 1977)

No transcorrer da história humana, o sentido da deficiência foi tomando diferentes interpretações. A deficiência já foi entendida, por exemplo, como sinal de forças ocultas e incontroláveis da natureza ou como fatalidade orgânica que acomete alguns indivíduos.

Nos dias de hoje, busca-se utilizar termos que dêem um sentido de maior inserção social para nomear os que sofrem qualquer tipo de deficiência. No entanto, essa terminologia utilizada ainda é questão controvertida. Às formas mais usualmente utilizadas pela literatura sobre o assunto, tais como deficiente, portador de deficiência, excepcional, portador de necessidades educativas (ou educacionais) especiais, podemos acrescentar outras expressões encontradas em artigos da revista americana Exceptional Children, utilizadas para referir-se a alunos que não acompanham as atividades escolares, tais como "crianças com discapacidades/desabilidades/inabilidades/ desvantagens" ou "crianças com alta incidência de dificuldades/problemas/distúrbios de aprendizagem". Alguns destes termos parecem tentativas de positivar juízos negativos. Uma

*Doutoranda em Educação. Mestre em Educação. Psicopedagoga. Professora do curso de Pedagogia da Universidade Bandeirante. Professora convidada do curso de Especialização em Psicopedagogia das Faculdades Integradas "Campos Salles". 
criança que tem desabilidade ou discapacidade é, na verdade, alguém que não tem habilidade ou capacidade.

Por outro lado, essas expressões podem se prestar a diluir a real dificuldade da criança: ela é excepcional em qual sentido? Tem desabilidade em relação a quê? Que tipo de necessidade educativa especial ela tem? Afinal, grosso modo, todos os seres humanos são desábeis ou incapazes em algum tipo de atividade. E, além do mais, nem todo portador de deficiência necessita efetivamente de serviços especializados para a promoção de sua escolarização, ainda que possa necessitar de intervenção terapêutica em função de suas condições físicas ou mentais.

Com relação à escola, essas novas denominações ampliam o universo de alunos que necessitam educação especial, abarcando todos aqueles "que estejam experimentando dificuldades temporárias ou permanentes na escola" (SANTOS, 1997). São classificados como alunos portadores de necessidades especiais não só aqueles com deficiências físicas, mentais ou sensoriais mais severas, mas também os que não se adaptam ao ambiente escolar por dificuldades emocionais, atitudinais ou sociais (por trás das quais podem estar péssimas condições de vida e falta de perspectivas).

Para Obiakor (1999), a educação precisa ter cuidado na identificação dos alunos com dificuldades, de forma a evitar preconceito e discriminação. Muitos deles são rotulados como crianças problemáticas, devido a expectativas irrealistas dos professores. É comum crianças apresentarem pobre desempenho na escola, não porque não tenham competência intelectual, mas porque sentem desamparo, têm baixa expectativa e negam a importância do esforço. Esse baixo desempenho as conduz a acreditarem cada vez menos nas suas capacidades e cada vez mais no poder da sorte. $\mathrm{O}$ que permeia tudo isso é o impacto das percepções no contexto em que elas interagem. Como os professores são indispensáveis nesse processo, a forma como as crianças são percebidas por eles afeta, sem dúvida, o sucesso da aprendizagem.
Além disso, a preocupação "politicamente correta" em buscar termos que dêem um sentido de maior inserção social, parece não ter sido acompanhada de práticas escolares mais inclusivas com relação aos alunos com algum tipo de deficiência. A despeito de um melhor entendimento das dificuldades da criança frente à sua escolarização, o problema continua sendo colocado na criança e no seu ambiente, dificilmente na escola que a acolhe. $\bigcirc$ modelo de escola não é questionado, ou seja, o desafio de educar crianças com diferenças visíveis não encontra correspondência nos sistemas educacionais. No mais das vezes, a responsabilidade recai exclusivamente, de forma velada ou explícita, nas competências (ou incompetências) individuais de alunos e professores. Dessa forma, a cultura e as normas da sociedade - representada pela escola - ficam naturalizadas.

A partir da Declaração de Salamanca - aprovada na Conferência Mundial de Educação Especial em 1994 - e no bojo das reformas educacionais implantadas nos anos 90 em vários países, incluindo o Brasil, "passou-se a considerar a inclusão dos alunos com necessidades educativas especiais em classes regulares como a forma mais avançada de democratização das oportunidades educacionais" (BUENO, 1997). A perspectiva da integração de crianças com necessidades educativas especiais no ensino regular não é nova, no entanto. $\mathrm{O}$ movimento de integração escolar surgiu na década de 70 . Na década de 80 , esse movimento é intensificado, já considerando que a classe regular é o melhor ambiente para alunos com deficiência. A partir dos anos 90 , surge um novo referencial - o da escola inclusiva - que continua propondo a escolarização de todos os alunos no mesmo contexto, porém sob outra perspectiva. Embora ambas tenham como norte a incorporação dessas crianças ao ensino regular, integração e inclusão não significam a mesma coisa. A integração tem como pressuposto que o problema reside nas características das crianças deficientes; a inclusão coloca a questão sob outra ótica, reconhecendo a existência das mais variadas diferenças: crianças deficientes e superdotadas, crianças de rua, crianças que trabalham, 
filhos de famílias nômades ou de minorias lingüísticas, étnicas, culturais, oriundos dos mais variados grupos marginalizados.

Para Bueno (1997), a primeira concepção, "ao afirmar que a dificuldade da incorporação reside nas características dos excepcionais, deixa implícita uma concepção acrítica da escola, isto é, considera que, de alguma forma, ela vem dando conta dos seus fins, pelo menos em relação aos alunos considerados normais" (p.9). A segunda concepção, "ao considerar a existência de múltiplas diferenças - originárias de condições pessoais, sociais, culturais e políticas - tem como pressuposto que a escola atual não consegue dar conta dessas diferenças, na medida em que proclama a necessidade de modificações estruturais da escola que aí está" (p.9), assumindo que a aprendizagem é que deve se adaptar às diferenças existentes entre as crianças e não o contrário. O movimento da escola inclusiva não diz respeito apenas à inclusão física do aluno, mas à possibilidade da escola realmente incorporar os aspectos concernentes às necessidades especiais dos alunos.

No entanto, se por um lado fala-se muito em educação inclusiva, por outro, o que vigora realmente no sistema educacional é, na melhor das hipóteses, a integração. $\mathrm{O}$ problema da deficiência ou desadaptação continua sendo atribuído às características da criança.

Obviamente, consideramos que só a defesa de uma escola que receba todos os alunos é compatível com a defesa de que todos os indivíduos têm direito à educação. No entanto, a perspectiva de uma escola imersa em relações desiguais, em que ela mesma mantém práticas seletivas e excludentes combinadas com a falta de informações sobre os supostos beneficiados, revela a extrema fragilidade da situação.

Em países como os Estados Unidos e o Canadá, onde o movimento da escola inclusiva encontra-se mais avançado, há o reconhecimento de que as soluções para a inclusão não são atingidas facilmente, uma vez que "a complexidade desta abordagem e a liderança que exige constituem desafios particularmente difíceis", co- mo destaca Porter (1995, p. 46). Para o autor, na perspectiva de uma verdadeira política de educação inclusiva, é imprescindível que os sistemas de ensino criem estruturas e programas que assegurem todo o apoio a professores e alunos. $\mathrm{O}$ empenho na eqüidade, tal como no acesso e na qualidade, requer um desenvolvimento contínuo de forma a conseguir melhores resultados para os alunos com necessidades especiais e, simultaneamente, criar escolas mais eficazes para todos os alunos. Eficazes, inclusive, no sentido de oferecer espaços de convivência que desestimulem a discriminação e o preconceito.

A situação atual do movimento da educação inclusiva pode ser ilustrada pelas conclusões a que chegaram os autores de três pesquisas referentes ao universo americano, recentemente publicadas na revista Excpetional Children: Obiakor (1999), Cook et al. (2000) e Morrison e D'Incau (2000).

Obiakor examina expectativas de professores sobre alunos de minorias excepcionais e seu impacto no autoconceito dos mesmos. Conclui que essas minorias continuam se confrontando com problemas multidimensionais na escola e na comunidade, sendo que um deles é a expectativa do professor. Isso porque, apesar das leis exigirem que as escolas de educação geral identifiquem, matriculem e instruam os alunos de forma a evitar a rotulação e a destruição de seus conceitos de eu, na prática esses processos são carregados com pressupostos e expectativas. Assim, por exemplo, para alguns professores, o desentendimento em questões culturais é interpretado como desrespeito, a pobreza pode significar pouca inteligência ou pouca habilidade em sair-se bem na vida.

Cook et al. examinam atitudes de professores a respeito de alunos com desabilidades incluídos em classes elementares de educação geral. Destacam que a política de inclusão é uma das mais contestadas dentro da reforma na educação contemporânea, que a corrente pró-inclusão tem prevalecido nos anos recentes e que os professores geralmente exibem opiniões positivas com relação ao "conceito geral de inclusão". Colocam, no entanto, a questão: "Até que ponto a 
crença conduz a mudanças na prática educativa?" Ressaltam que não há provas empíricas de que essas opiniões positivas dos professores em relação à inclusão resultem na melhoria da eficácia docente e em melhores resultados por parte dos alunos. Concluem que a atitude do professor, mais que sua opinião a respeito do conceito abstrato de inclusão, é o predictor da qualidade da educação oferecida aos alunos.

Morrison e D'Incau examinam trajetórias de desenvolvimento individual de alunos mal-adaptados que precedem a recomendação de que sejam expulsos da escola. Concluem que, enquanto há uma grande preocupação em manter as escolas seguras e em ordem (política de tolerância zero), é pequeno o conhecimento sobre a significância pessoal e social da expulsão, bem como sobre as implicações da exclusão do contexto educacional de alunos "pegos na teia da tolerância zero". Apontam ainda que estudos sobre esses estudantes excluídos revelam um grupo heterogêneo, sendo que poucos apresentam um real perigo para os demais. Como não recebem a tempo o suporte e a assistência que necessitam, os tratamentos escolhidos são a expulsão e a exclusão, utilizadas como "medida disciplinar final", inclusive com relação a crianças cada vez mais jovens.

O que chama particularmente a atenção nesses textos é o preconceito presente no ambiente escolar contra os alunos que apresentam comportamento inadaptado ou desajustado, geralmente rotulados como "indisciplinados". Assim, uma condição de desabilidade muito severa acaba servindo como mecanismo protetor: para os professores, esses alunos merecem compaixão. Com relação àqueles que apresentam dificuldades brandas, mas são "bonzinhos, esforçados", o professor consegue ter uma atitude de preocupação, envolver-se pessoalmente e encarar como desafio seu progresso acadêmico. Porém, a intolerância é total contra os que, a dificuldades de aprendizagem associam-se problemas comportamentais. Geralmente, esses problemas são associados ao que a escola interpreta como problemas sociais. Não é por acaso que a maioria dos alunos rotulados como "desadaptados" pertence a grupos étnicos minoritários.

O que se observa é uma associação perversa entre grupos minoritários e dificuldades na escola. No mais das vezes, esse fato oculta estereótipos generalizados, diferenças individuais interpretadas à luz de valores culturais, expectativas irrealistas de professores que afetam a avaliação de estudantes, rotulações e generalizações discriminatórias. Parece lógico associar a "má adaptação" a preconceitos contra grupos que não se enquadram no "american way of life", seja por problemas culturais, seja por problemas sociais, a maioria das vezes associados a problemas econômicos.

Nos Estados Unidos, na esteira da alta incidência de violência escolar, desenvolve-se a política de "tolerância zero" para porte de armas, comportamento ameaçador e envolvimento com drogas. No Brasil, quando conversamos com equipes escolares ou acompanhamos os noticiários, o problema de controle da disciplina dos alunos, as reclamações sobre o crescente desrespeito a professores, o aumento da violência extra e intra-muros é assunto sempre recorrente. A verdade é que, por trás da violência escolar, o que se encontra é uma criança ou adolescente sem perspectivas de vida dentro da sociedade tal como ela se apresenta, ou melhor, cujas perspectivas encontram-se apenas no campo informal ou, pior, no ilegal.

Vejamos! Por conta do desenvolvimento tecnológico e da globalização, há uma nova configuração econômico-social mundial, sendo que parcelas cada vez maiores da população de países periféricos têm na inclusão econômica e social um horizonte cada vez mais distante. Ao mesmo tempo, na educação há o movimento da escola inclusiva, que parte de um conceito ampliado de inclusão, abarcando as mais variadas diferenças entre o alunado. A escola e seus educadores encontram-se em permanente situação de ambigüidade e conflito.

O que se propõe é uma mudança de mentalidades e de atitudes dentro da escola, e elas não são fáceis de ser alteradas. Propõe-se que o edu- 
cador, socializado em e para uma escola de massas, homogeneizadora, que tem como meta igualar a todos, passe a conduzir uma aprendizagem que abarque as mais variadas diferenças existentes entre os alunos. E, além disso, uma questão está sempre presente: é possível que mude a escola, passando a desenvolver uma educação inclusiva, sem a concomitante mudança na sociedade, que continua tendo a exclusão como um de seus pilares? Ou será esse mesmo o papel da escola: conformar cidadãos à sociedade injusta?

Mesmo consciente de toda a questão econômico-social que se encontra por trás da problemática escolar, e também de quanto é difícil analisar de forma isolada as variáveis que interferem nas atitudes dos professores, estudos dessas atitudes se fazem fundamentais para entendermos os mecanismos de exclusão que permeiam a prática pedagógica.

Tendo por foco as atitudes de preconceito que os professores apresentam com relação a alunos com comportamento inadequado, arriscamos algumas explicações a partir da teoria crítica de Adorno. A pergunta que fazemos é: o preconceito das equipes escolares em relação ao aluno inadaptado, que apresenta problemas comportamentais e atitudinais, revela o quê?

Tradicionalmente, têm sido atribuídos aos professores, em nosso meio, dois papéis básicos: ensinar alunos e ajustá-los à sociedade. É lógico, portanto, que professores dêem clara preferência a alunos que não impeçam esses desígnios. Professores precisam sentir-se valorizados pela tarefa que desempenham. Assim, é natural que eles se sintam recompensados com a alta realização e a atitude apropriada dos alunos que apresentam bom desempenho e bom comportamento, com um baixo investimento docente em tempo e trabalho. Com alunos com desempenho escolar mais fraco (desde que sejam bem comportados), a recompensa que os professores recebem consiste em sentir que o esforço extra que fazem é compensado pela possibilidade de alcançar sucesso onde outros falharam. Agora, os mais rejeitados são os estudantes que associam dificuldades de aprendizagem a comportamentos inadequados. Eles constituem fontes de dificuldade e frustração contínuas para seus professores, pois contrariam o papel e os limites comportamentais da escola.

Ampliando nosso foco para a sociedade, vemos que os que têm uma condição distinta (física, sensorial, comportamental, social, cultural) são compreendidos como seres constituintes de um impedimento para a realização dos objetivos imediatos da sociedade, quais sejam, a produtividade e o lucro. A única saída vislumbrada é o ajustamento à sociedade. Esta impede a emergência e a afirmação de modos de ser diferenciados, através dos processos de formação em que a adaptação é reforçada cada vez mais. $\mathrm{O}$ aluno com deficiência ou com alguma diferença indesejada pela sociedade, que sofre com a discriminação e o preconceito, não tem clareza sobre a origem do sofrimento que sente. O desconhecimento de que o sofrimento é gerado pela sociedade leva o aluno discriminado a acreditar que o problema é seu, individual, gerando autoconceito negativo. Alguns insistem na adaptação, como forma de não serem vistos como incompetentes. Outros partem para a afronta, para o revide cego contra a sociedade que, ao mesmo tempo em que exige adaptação, a impede. Parece claro que esse jovem se comporta de forma defensiva, porque a sociedade tem como base a ameaça, mas, como já foi dito, ela própria se encarrega de impossibilitar essa consciência. Como achamos natural existir a dominação, a submissão do outro é fundamental e sua rebeldia nos incomoda.

Além disso, o preconceito ao portador de deficiência dá-se pela lembrança da fragilidade. Como nossa sociedade cultua a força, aquele que porta uma deficiência lembra a fragilidade que se quer negar. $\mathrm{O}$ professor que vê o aluno com deficiência como não portador da idéia de humanidade, não se identifica com ele. Não se identificando, acirra a discriminação. A lembrança da fragilidade humana, da diferença compreendida como obstáculo à inserção funcional na sociedade, determina a prática da negação social.

Todos aqueles que se adaptam, renunciam à própria autonomia. Essa renúncia à autonomia 
por parte dos adaptados - e o professor pode ser assim caracterizado - é algo internalizado, retornando sob a forma de agressão e discriminação àqueles que demonstram algum tipo de resistência. É o que acontece com o aluno com dificuldade de aprendizagem associada ao mau comportamento. Recusando-se à adaptação ele é rejeitado, pois impede duplamente o professor no exercício de seu papel: ensinar e adaptar. Assim, professores são acometidos por idiossincrasias, ou pela repugnância a tudo o que não se ajusta ao modelo adotado, como destacam Adorno e Horkheimer (1985): "Tudo o que não se ajustou inteiramente ou que fira os interditos em que se sedimentou o progresso secular tem um efeito irritante e provoca uma repugnância compulsiva" (p. 168).

O desadaptado pode, ainda, despertar no professor a lembrança daquilo que ele próprio gostaria de ser e não pode, ativando o comportamento projetivo, em que "os impulsos que o sujeito não admite como seus e que, no entanto, lhe pertencem, são atribuídos ao objeto: a vítima em potencial" (ADORNO e HORKHEIMER, 1985, p. 174). O patológico não é a projeção em si, mas a ausência de reflexão impedida pela própria cultura que a caracteriza. Devido ao impedimento da imaginação, o professor não concebe que o aluno possa ser diferente dele. Em um mundo de produção em série, a estereotipia substitui o pensamento e a reflexão.

A título de conclusão, podemos destacar que, a despeito de já existir um conhecimento produzido sobre a possibilidade de escolarização e aprendizagem de alunos com deficiência em ambientes não segregados, ainda prevalece na sociedade a atitude de discriminação e preconceito a esses indivíduos. Mesmo considerando que as propostas pedagógicas contemporâneas buscam eliminar as práticas de segregação, é perceptível o estranhamento da sociedade quando nega o acesso à escola aos que têm uma condição distinta (física, comportamental, cultural...), na medida em que não provê seus espaços com o necessário para sua permanência - recursos materiais, capacitação de professores, adaptações arquitetônicas e outras. $\mathrm{O}$ sistema educacional não é moldado com o desafio de educar estudantes portadores de complexas características individuais e que vêm de famílias e situações comunitárias complexas. Percebe-se a confusão dos educadores sobre como melhor atender estudantes com aprendizagem complexa e com problemas emocionais, sociais e comportamentais.

\section{REFERÊNCIAS BIBLIOGRÁFICAS}

ADORNO, T. H; HORKHEIMER, M. Elementos do anti-semitismo. In: Dialética do esclarecimento. Rio de Janeiro: Zahar, 1985. p. 157-194.

ADORNO, T. H. Educação após Auschwitz. In: Educação e emancipação. Rio de Janeiro: Paz e Terra, 1995. p. 119-138.

ADORNO, T. H. Opinión, loucura e sociedade. In: Intervenciones. Caracas: Monte Ávila, 1969. p. 137-160.

BUENO, José G. da S. Excepcionalidade, história e conceito. In: Educação especial brasileira: integração/segregação do aluno diferente. São Paulo: EDUC, 1993. p.27-40.

. Crianças com necessidades educativas especiais, política educacional e a formação de professores: generalistas ou especialistas. Revista Brasileira de Educação Especial, n. 5, p. 7-25, 1997.

COOK, Brian G. et al. Teacher's attitudes toward their included students with disabilities. Exceptional Children, v. 67, n. 1, p. $115-135,2000$.

JENKINS, Joseph R.; ODOM, Samuel L.; SPELTZ, Matthew L. Effects of social integration on preschool children with handicaps. Exceptional Children, v. 55, n. 5, p. 420-428, Feb. 1989.

KLAUSMEIER, Herbert J. Manual de Psicologia Educacional. São Paulo: Harbra, 1977.

KLINGNER, Janette; VAUGHN, Sharon. Student's perceptions of instruction in inclusion classrooms: implications for students with learning disabilities. Exceptional Children, v. 66, n. 1, p. 23-37, 1999.

MAZZOTTA, Marcos J. S. História da educação especial no Brasil. In: Educação especial no Brasil: história e políticas públicas. São Paulo: Cortez, 1996. p. 27-49.

MORRISON, Galé M.; D'INCAU, Bárbara. Developmental and service trajectories of students with disabilities recommended for expulsion from school. Exceptional Children, v. 66, n. 2, p. 257-272, Winter 2000. 
OBIAKOR, E. Festus. Teacher Expectations of Minority Learners: impact on "Accuracy" of self-concepts. Exceptional Children, v. 66, n. 1, p 39-53. 1999.

ODOM, Samuel L.; DEKLYEN, Michelle; ENKINS, Joseph R. Integrating Handicapped and Nonhandicapped Preeschoolers: Developmental Impact on Nonhandicapped Children. Exceptional Children, v. 51, n.1, p. 41-48, 1984.

PORTER, Gordon. Organização das escolas: conseguir o acesso e a qualidade através da inclusão. In: Dimensões formativas: caminhos para as escolas inclusivas, 1994. p. 34-48. Trabalho apresentado à Conferência Mundial sobre "Necessidades Educativas Especiais: acesso e qualidade", Salamanca, 4 a 10 de junho de 1994.

SANCHES, Isabel Rodrigues. Necessidades Educativas: conceito e âmbito de aplicação. In: Necessidades educativas especiais e apoios e complementos educativos no quotidiano do professor. Porto: Porto, 1996. p. 9-20.

SANTOS, Mônica Pereira dos. A Inclusão da criança com necessidades educacionais especiais. 1997. Mimeografado.

SILVA, Shirley. A multiplicidade de se construir o especial: os "especiais" e a crise derivada na educação especial. In: Educação Especial: um esboço de política pública. 2000. Tese (Doutorado). Faculdade de Educação/USP, p. 10-28. 